\title{
THE PHENOLOGY AND DISTRIBUTION OF APHIDS IN CALIFORNIA ALFALFA AS MODIFIED BY LADYBIRD BEETLE PREDATION (COLEOPTERA: COCCINELLIDAE)
}

\section{Journal Article}

Author(s):

Gutierrez, A. P.; Summers, C. G.; Baumgaertner, J.

Publication date:

1980

Permanent link:

https://doi.org/10.3929/ethz-b-000423058

Rights / license:

In Copyright - Non-Commercial Use Permitted

Originally published in:

The Canadian Entomologist 112(5), https://doi.org/10.4039/Ent112489-5 


\title{
THE PHENOLOGY AND DISTRIBUTION OF APHIDS IN CALIFORNIA ALFALFA AS MODIFIED BY LADYBIRD BEETLE PREDATION (COLEOPTERA: COCCINELLIDAE) ${ }^{1}$
}

\author{
A. P. Gutierrez \\ Division of Biological Control, Department of Entomological Sciences, University of California, \\ Berkeley 94720 \\ C. G. Summers \\ Division of Entomology and Parasitology, Department of Entomological Sciences, University of \\ California, Berkeley 94720 \\ J. BAUMgAERTNER \\ Entomologisches Institut ETH, $\mathrm{CH}-8000$ Zurich, Switzerland
}

\begin{abstract}
Can. Ent. 112: 489-495 (1980)

The phenologies and distributions of pea aphid (Acyrthosiphon pisum (Harris)), blue alfalfa aphid (A. kondoi (Shinji)), and spotted alfalfa aphid (Therioaphis maculata (Buckton)) were intensively studied in California alfalfa. The results showed, as expected, that aphid populations across all densities were aggregated; but that ladybird beetle (Hippodamia convergens (G.-M.)) predation increased the degree of aggregation. The distribution parameters of the aphids were estimated using methods developed by Iwao and Kuno (1971).
\end{abstract}

\section{Résumé}

Les phénologies et distributions du puceron du pois, Acyrthosiphon pisum (Harris), A. kondoi (Shinji), et Therioaphis maculata (Buckton) ont été étudiées intensivement sur la luzerne en Californie. Les résultats ont montré, tel qu'attendu, que les populations de pucerons forment des agrégats à toutes les densités; et que la prédation par la coccinelle Hippodamia convergens (G.-M.) augmente le degré d'agrégation des pucerons. Les paramètres décrivant la distribution des pucerons ont été estimés grâce à des méthodes mises au point par Iwao et Kuno (1971).

The distribution and abundance of prey in the field greatly influence the success of predators and, via nutrition, their survival, growth, and reproduction. A knowledge of these relationships is essential if satisfactory field models of predator-prey interactions are to be developed. This paper is part of a series on the interactions of pea aphid (Acyrthosiphon pisum (Harris)), blue alfalfa aphid (A. kondoi (Shinji)), and spotted alfalfa aphid (Therioaphis maculata (Buckton)) and their ladybird beetle predator Hippodamia convergens (G.-M.) in alfalfa. In this paper we report an analysis of the phenology and distribution of these organisms, and use this information to estimate the influence of prey distribution on predation success of $H$. convergens in the field.

\section{Methods}

\section{Analysis of Prey Distribution in the Field}

Lloyd (1967) developed a method ("Patchiness" $=X^{*} / \bar{X}$ ) which is affected little by changes in density, to measure the distributions of organisms in nature. Patchiness is defined as the ratio of mean crowding $\left(X^{*}\right)$ to the mean $(\bar{X})$, where $X^{*}$ is defined as

$$
X^{*}=\bar{X}+\left(S^{2} / \bar{X}-1\right)
$$

and $S^{2}$ is the population variance. Values of $X^{*} / \bar{X}$ less than, equal to, or greater than 1 indicate uniform, random, and aggregated distributions respectively. Iwao and Kuno (1971) showed that the slope $(\beta)$ of the regression line of $X^{*}$ on $\bar{X}$ provided an equivalent measure of dispersion and, in addition, found that the intercept $(\alpha)$ was a measure of the units of that dispersion (i.e. $\alpha+1$ ).

'This publication was supported in whole or in part by the National Science Foundation and the Environmental Protection Agency, through grants (NSF DEB-75-04223 and NSF DEB-77-25260) to the University of California. 
These methods have been used successfully in California to describe the distribution of Egyptian alfalfa weevil in alfalfa (Christensen et al. 1977) and various predators in cotton (Byerly et al. 1978).

Sampling procedures. Alfalfa stems were convenient sampling units for measuring interaction and dispersion of both the aphid prey and the ladybird beetle predator in alfalfa. Population densities of all species were sampled by selecting 100 stems at random within designated sites at Albany and Fresno, California during 1977. The Albany site has mild weather nearly all year round, while Fresno, which is located in the San Joaquin Valley, has moderately cold winters and very hot, dry summers. The stems were handled individually, in a manner not likely to dislodge the insects, cut at the base, and placed separately in a glass test tube containing $70 \%$ alcohol. The tubes were taken to the laboratory and the specimens counted. While the two Acyrthosiphon spp. from Fresno were identified to species, the Albany aphid samples were not separated because the necessary manpower was unavailable. Usually field samples were collected every other day during periods of rapid population growth (spring and fall), and once weekly during other times of the year.

Visual counts of beetle adults at Albany were recorded per 30.48 meter row of alfalfa, while those at Fresno were recorded per 100 stems.

\section{Results}

Albany. The phenologies of the total blue plus pea aphid populations, as well as $H$. convergens adults, are shown in Fig. 1. The aphid population remained low throughout the sampling period; but fluctuations that did occur appeared to be greatly

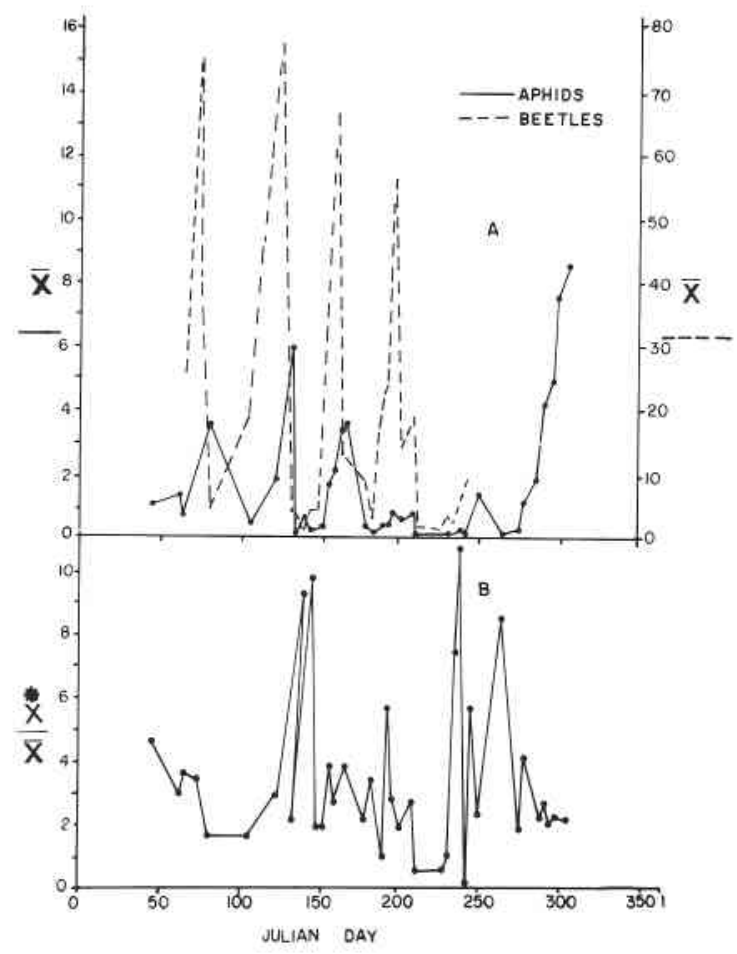

FIG. 1. (A) A plot of the mean number of aphids per 100 stems (— convergens adults per 30.48 meter rows of alfalfa (- - -) (i.e. the alfalfa was grown in rows, cf. Fraser and Gilbert 1976), and (B) a plot of $X^{*} / \bar{X}$ for aphid numbers over time (see text for a full discussion). 
Table I. Summary of regression statistics of mean crowding $\left(X^{*}\right)$ on the sample mean $(\bar{X})$ for two California locations

\begin{tabular}{|c|c|c|c|c|c|}
\hline Location & Species & $\beta=$ slope (S.E.) & $\alpha=$ intercept (S.E.) & $R$ & $N$ \\
\hline Albany & $\mathbf{B A A}+\mathbf{P A}$ & $2.052(0.111)$ & $1.245 \quad(0.272)$ & 0.918 & 61 \\
\hline Fresno & $\begin{array}{l}\text { BAA } \\
\text { PA } \\
\text { SAA }\end{array}$ & $\begin{array}{l}2.293(0.146) \\
1.642(0.086) \\
1.720(0.085)\end{array}$ & $\begin{array}{rr}11.935 & (4.361) \\
6.535 & (2.507) \\
3.467 & (0.961)\end{array}$ & $\begin{array}{l}0.921 \\
0.934 \\
0.934\end{array}$ & $\begin{array}{l}46 \\
52 \\
37\end{array}$ \\
\hline Fresno & $\begin{array}{c}\text { BAA before } \\
\text { and } \\
\text { after } \\
\text { peak predation }\end{array}$ & $\begin{array}{l}2.010(0.271) \\
4.815(0.934)\end{array}$ & $\begin{array}{c}27.617(11.992) \\
2.567 \quad(2.558)\end{array}$ & 0.865 & 20 \\
\hline
\end{tabular}

Abbreviations: BAA, blue alfalfa aphid; PA, pea aphid; SAA, spotted alfalfa aphid.

influenced by beetle predation, as the adult beetle population increases and decreases followed those of the aphids. This is not unexpected, as $H$. convergens is well known to be an effective predator of the aphids in alfalfa (Neuenschwander et al. 1977), and the ladybird beetles are especially effective at low prey densities (Frazer and Gilbert 1976). We cannot tell how much of the change in beetle density was due to immigration of adults from outside of the field.

In this study, the ratio $X^{*} / \bar{X}$ fluctuated considerably due to unavoidably low population sampling errors (i.e. large changes in $S^{2}$ affect $X^{*}$ and, hence, $X^{*} / \bar{X}$ - see [1] and Fig. 1), and to the fact that predation by the beetles greatly altered the distribution of colonies in the field (i.e. the distance between alfalfa stems with colonies appeared to greatly increase as predator activity increased). The value of $X^{*} / \bar{X}$ appears to stabilize near 2.0-2.75 after day 275 (early September) when the beetles left the field.

A plot mean crowding $\left(X^{*}\right)$ on the population mean $(\bar{X})$ is shown in Fig. 2. The slope of the regression is greater than $1(\beta=2.05)$ (see Table I) indicating that the aphids were moderately aggregated (Iwao and Kuno 1971), while the intercept is significantly greater than zero $(\alpha=1.25)$ indicating that the unit of contagion was greater than 1 (i.e. $\alpha+1$ ). In general terms, this means that, even though aphid populations were low, they occurred in small colonies.

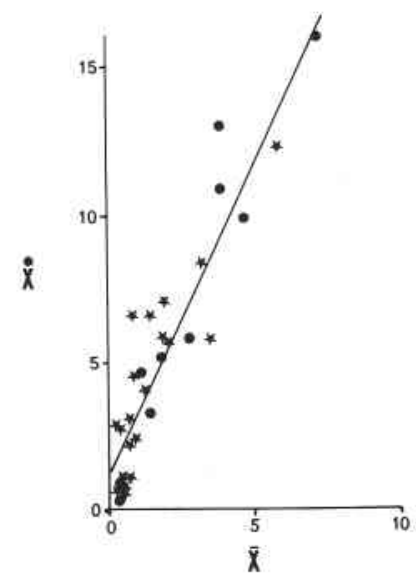

FIG. 2. A plot on a per stem basis of mean crowding $\left(X^{*}\right)$ on the mean number of aphids $(\bar{X})$ per stem. Blue and pea aphids not separated. The symbols $(\star)$ and $(\bullet)$ depict data before and after predation. 
Fresno. The three species of aphid were counted separately and their phenologies and patterns of $X^{*} / \bar{X}$ are depicted in Fig. 3. Blue alfalfa aphid was most abundant during late winter - early spring, while pea aphid and spotted alfalfa aphid populations increased only during late summer - early fall. Numerous studies have shown that pea aphid, in contrast to spotted alfalfa aphid, does not do well during the hot summer in the San Joaquin Valley, where daily temperatures often exceed $40^{\circ} \mathrm{C}$ (Messenger 1964; Gutierrez and van den Bosch 1970). Blue alfalfa aphid would likewise be expected to perform poorly in this area, as its response to high temperature is very similar to that of pea aphid. Nonetheless, sufficient aphids were present in the field to keep the adult beetle from migrating and for some reproduction to occur (see Fig. 3). Prior to the accidental introduction of blue alfalfa aphid into California, pea aphid populations normally had both spring and fall flushes of population growth.

The apparent displacement of pea aphid by blue alfalfa aphid during spring has occurred throughout California, and may have been caused for the following reasons: (1) blue aphid populations reproduce at slightly lower temperatures (i.e. the lower

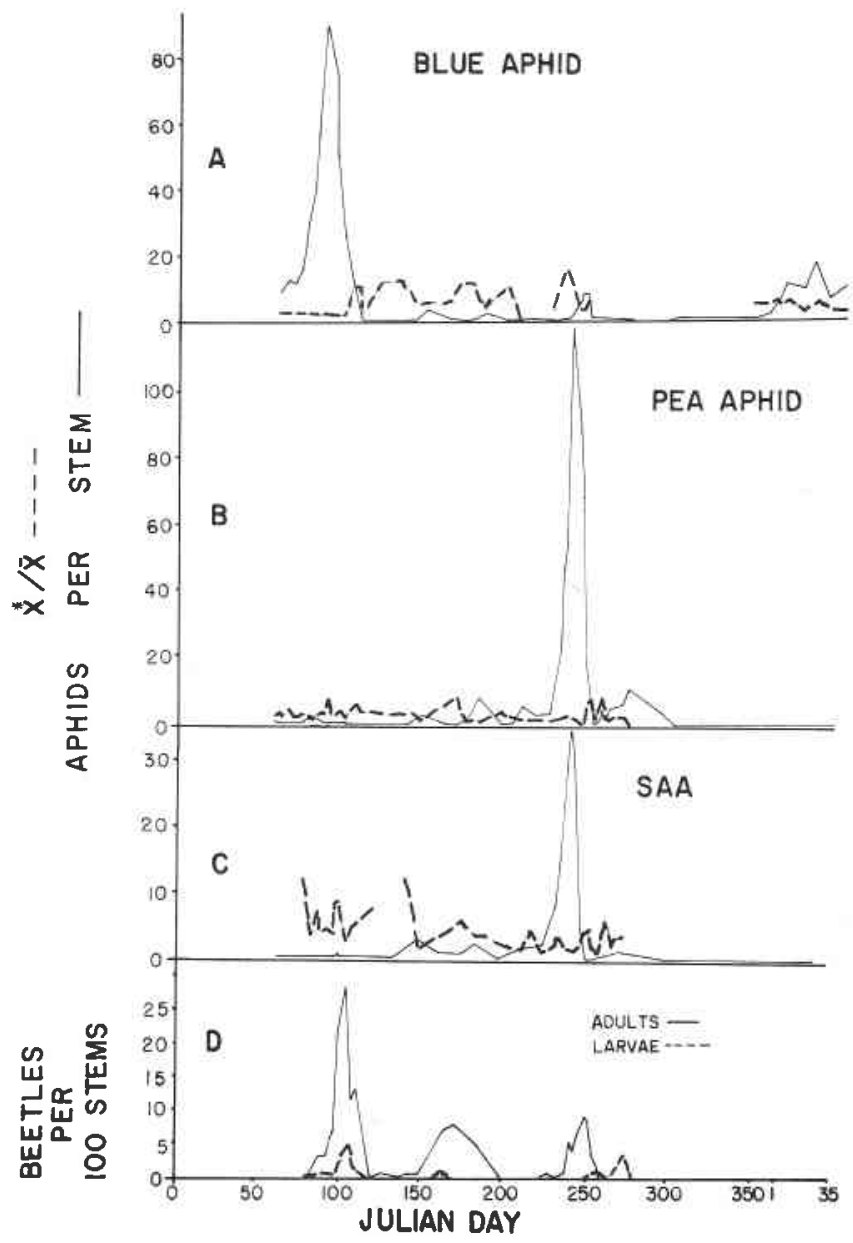

FIG. 3. A plot of the mean number $(\bar{X})$ of (A) blue alfalfa aphid, (B) pea aphid, (C) spotted alfalfa aphid, and (D) $H$. convergens adults and larvae per 100 alfalfa stems. The ratio of $X^{*} / \bar{X}$ per stem is plotted as the dotted line for $\mathrm{A}, \mathrm{B}$, and $\mathrm{C}$ (see text for full discussion). 
developmental threshold for the blue aphid is approximately $0.5^{\circ} \mathrm{C}$ lower than that of pea aphid) (C. G. Summers unpub.); (2) the pea aphid has been forced to a niche lower on the stem by blue aphid and, hence, it is more available to predators that cross from stem to stem at mid height (J. U. Baumgaertner and A. P. Gutierrez unpub.).

The overwintered adult beetles arrived in the field some time before Julian day 80 (mid-March) when they were first detected in the samples. Because blue aphid populations were high, the beetles were able to reproduce and drive the aphid population down (see Fig. 3a). The patchiness values $\left(X^{*} / \bar{X}\right)$ for blue aphid had stabilized near 2 before predation, but fluctuated between 6 and 15 after the population was decimated. Patchiness values for pea aphid were more stable than those for blue aphid, fluctuating between 1.5 and 4 , but some major fluctuations occurred during peak periods of predation. Patterns similar to those of pea aphid were found for spotted alfalfa aphid.

Plots of $X^{*}$ on $\bar{X}$ for each of the species (Fresno) are shown in Fig. 4A-C, and a summary of the regression statistics is given in Table I. Only the slope and intercept for the blue aphid regression were significantly different from those of pea and spotted alfalfa aphid. In all cases, the slopes were greater than 1 , indicating that the aphids were aggregated; while the intercept values significantly greater than zero indicate that the unit of aggregation was greater than 1. A further examination of the blue alfalfa aphid data shows that the slope of the regression $(4 \mathrm{~A} \ldots$...) after peak predation (i.e. day 100) is greater than before day $100(4 \mathrm{~A} \ldots$-) and those of the other species $(4 \mathrm{~B}, \mathrm{C})$. The intercept value before day 100 is large, while that for the data after 100 is much smaller. These results (see Table I) would indicate that predation increased the degree of aggregation in blue aphid $(\beta)$, but
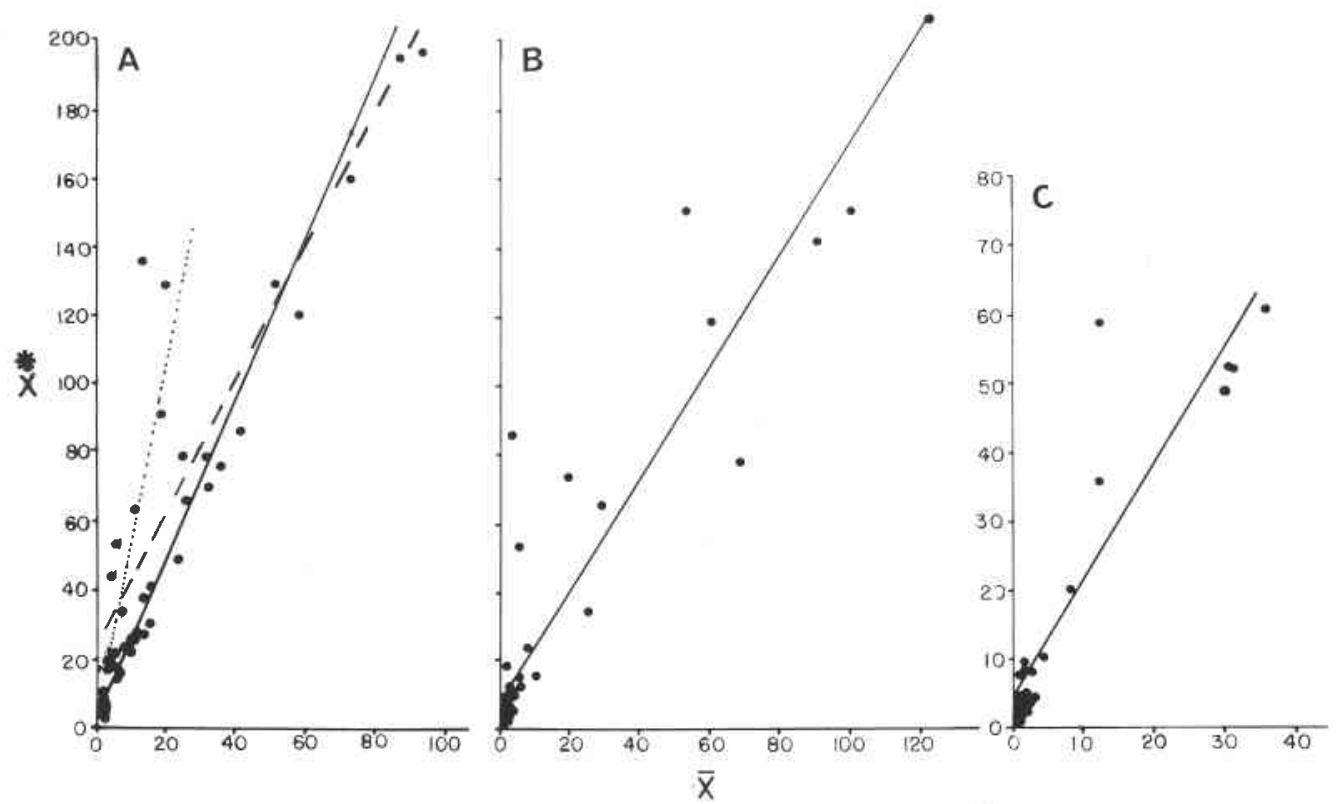

FIG. 4. A plot on a per stem basis of mean crowding $\left(X^{*}\right)$ on the mean $(\bar{X})$ : (A) blue alfalfa aphid, (B) pea aphid, and (C) spotted alfalfa aphid. In Fig. A, the solid line $(\longrightarrow$ is the regression for blue aphid including all data points, the dashed line (- - -) includes data points before peak predator activity (day 105), while the dotted line (. . .) is the regression line for those data points shortly after peak predator activity (day 100). 
caused their unit of aggregation to become smaller $(\alpha)$. A similar comparison was not possible for the other species because hot weather as well as predation affected their phenologies and their distributions.

Similar analyses were not possible for the beetles because the numbers per stem were very low (Fresno), only one estimate per collection date was available for Albany, and, furthermore, the units were different between sites.

\section{Discussion}

Aphid populations in alfalfa were always aggregated in the range of population densities observed in our experiments, but it was obvious that predation by $H$. convergens greatly increased blue alfalfa aphid aggregation. The biology of aphids suggests that aggregation would occur in the absences of predators, as the aphids are relatively immobile, reproduce parthenogenetically and form colonies. For example, a single blue alfalfa aphid female could easily produce 5-6 progeny per day at $21^{\circ} \mathrm{C}$, and 1 or more days' production may occupy the same stem. Dispersal of the progeny may occur via emigration of winged forms to distant stems or of wingless forms to nearby stems. Predation by beetles would tend to destroy the colony by consuming the aphids or causing them to flee the stem. Thus, we can easily envision a case where increased predation leads, not only to a lower average density, but also to a smaller proportion of the stems being colonized-i.e. increasing the distance between colonies. By contrast, Frazer and Gilbert (1976) observed a more uniform distribution of pea aphids in alfalfa after predator attack. The activity of the predators would tend to lower their own average predation success rate. This notion is well illustrated by the Fresno blue alfalfa aphid data which show that $X^{*}$ / $\bar{X}$ values were stable before predation but fluctuated broadly during periods of predator activity. The other species exhibited similar but less defined influence of predators on their dispersion patterns. In addition, sampling errors at low population densities also influence $X^{*} / \bar{X}$, and it is difficult to separate these effects.

It is not meaningful to describe the dispersion pattern of the beetle on a per stem basis, as individual adult beetles can cover several stems in a very brief period. The natural unit for sampling adults should be much larger, for example $0.1 \mathrm{~m}^{2}$, which is approximately 50 stems. First instar larvae are more likely to be limited to individual stems, but their densities are usually so low that an inordinately large sample is required to ascertain their dispersion. The sampling unit for older beetle larvae must increase as their vagility increases.

Ladybird beetle adults and larvae do not perceive their prey at great distance; nor do they aggregate, except as adults during winter diapause or during random mating encounters. Their searching appears to be an entirely random process. Thus, if we are to estimate their predation success, we must be able to compute it given different expectations of encounter; and this changes not only with density, but also with the distribution of the prey.

Patchiness is related to the negative binomial $k$ in the following way (Iwao and Kuno 1971):

and hence

$$
X * / \bar{X}=1+1 / k
$$

$$
k=\bar{X} /\left(X^{*}-\bar{X}\right) \text {. }
$$

This relationship is important in modeling predator-prey interactions, because, by knowing $k$ and $\bar{X}$, we can define the probability density function for the distribution of prey. (N.B. $\bar{X}$ is estimated by the model at each time step and $X^{*} / \bar{X}=(\alpha+\beta \bar{X}) / \bar{X}$ has characteristic values for the three prey species once 
predation has begun.) Hence, a corrected mean prey density $\left(\bar{X}_{c}\right)$ per effective unit in the field (e.g. per stem) can be computed as follows:

$$
\bar{X}_{c}=\sum_{r=0}^{m} r P\{r\},
$$

where $r$ is the frequency class $(r=0,1,2, \ldots, m)$ and $P\{r\}$ is the probability of $r$ from a negative binomial distribution with estimated parameters $k$ and $\bar{X}$. In the notation of predator-prey models, $\bar{X}_{c}$ is equivalent to the number of prey available $\left(N_{0}\right)$ (see Christensen et al. 1977).

\section{References}

Byerly, K. F., A. P. Gutierrez, R. E. Jones, and R. F. Luck. 1978. A comparison of sampling methods for some arthropod populations in cotton. Hilgardia 46: 256-282.

Christensen, J. B., A. P. Gutierrez, W. R. Cothran, and C. G. Summers. 1977. The within field spatial pattern of the larval Egyptian alfalfa weevil, Hypera brunneipennis (Coleoptera: Curculionidae): An application of parameter estimates in simulation. Can. Ent. 109: 1599-1604.

Frazer, B. and N. E. Gilbert. 1976. Coccinellids and aphids: A qualitative study on the impact of adult ladybirds (Coleoptera: Coccinellidae) preying on the field populations of pea aphids (Homoptera: Aphididae). J. ent. Soc. Br. Columb. 73: 33-56.

Gutierrez, A. P. and R. van den Bosch. 1970. Studies on host selection and host specificity of the aphid hyperparasite Charips victrix (Hymenoptera: Cynipidae). 1. Review of hyperparasitism and the field ecology of Charips victrix. Ann. ent. Soc. Am. 63: 1345-1354.

Iwao, S. and E. Kuno. 1971. An approach to the analysis of aggregation patterns. pp. 311-335 in B. P. Patiel, E. C. Pielou, and W. E. Waters (Eds.), Statistical Ecology, Vol. I: Spatial patterns and statistical distributions. Penn. State Univ. Press.

LLoyd, M. 1967. Mean crowding. J. Anim. Ecol. 36: 1-30.

Messenger, P. S. 1964. Use of life tables in a bioclimatic study of an experimental aphid-braconid wasp host-parasite system. Ecology 45: 119-131.

Neuenschwander, P., K. S. Hagen, and R. F. Smith. 1977. Predation of aphids in California's alfalfa fields. Hilgardia 43: 53-78.

(Received 5 July 1979) 